\title{
Force Production Patterns of Muscles Surrounding Knee During Running and Cutting Maneuvers: A Musculoskeletal Modeling Approach
}

\author{
Jusung Lee ${ }^{1}$, Kichung Lee ${ }^{2}$, Jeheon Moon ${ }^{3}$, Tejin Yoon ${ }^{1,4}$ \\ ${ }^{1}$ Interdisciplinary Program in Biohealth-machinery Convergence Engineering, Kangwon National University, Chuncheon, \\ Republic of Korea \\ ${ }^{2}$ Department of Physical Education, Chuncheon National University of Education, Chuncheon, Republic of Korea \\ ${ }^{3}$ Department of Physical Education, Korea National University of Education, Cheongju, Republic of Korea \\ ${ }^{4}$ Department of Physical Education, Kangwon National University, Chuncheon, Republic of Korea
}

Received: October 5, 2021

Accepted: October 27, 2021

Published online: January 31, 2022

Keywords:

Cutting

Individual Muscle Force

Musculoskeletal Modeling

Running

Static Optimization
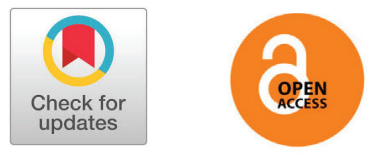

\section{ABSTRACT}

OBJECTIVES The purpose of this study was to investigate the force production patterns of individual muscles surrounding the knee during running (RUN) and cutting (CUT) tasks.

METHODS Thirteen women $(24.2 \pm 3.5 \mathrm{yrs}, 162.8 \pm 6.0 \mathrm{~cm}, 55.3 \pm 6.2 \mathrm{~kg})$ performed a series of running and cutting tasks. Running and cutting motions were recorded using a motion capture system and ground reaction force (GRF) was recorded using a force plate. Three-dimensional knee angle, ground reaction force, and knee joint moment were calculated using Visual3D software. OpenSim musculoskeletal modeling software was used to calculate the force of individual muscles including the medial hamstring, biceps femoris long head, biceps femoris short head, rectus femoris, vastus medialis, vastus lateralis, gastrocnemius medialis, and gastrocnemius lateralis. All data were analyzed for loading response (or weight acceptance), mid-stance, and final push-off periods, respectively and were compared between two tasks.

RESULTS At loading response: external rotation angle, medial and vertical GRFs, and valgus moment for the CUT task were greater than those of the RUN task. Compared to the RUN task, the CUT task showed: 1) an increase in lateral hamstring muscle force at weight acceptance, 2) a decrease in hamstring muscle force and an increase in medial vastus muscle force at mid-stance, and 3) an increase in lateral gastrocnemius muscle force at final push-off.

CONCLUSIONS Selective force production patterns of muscles surrounding the knee seem to offset the external load caused by the cutting motion. We anticipate that our results will provide basic data for future training programs designed to prevent noncontact knee injuries.

(C) The Asian Society of Kinesiology and the Korean Academy of Kinesiology
서론

전방십자인대(anterior cruciate ligament; ACL) 파 열은 무릎 부상의 $50 \%$ 이상을 차지할 만큼 빈번한 부상

*Correspondence: Tejin Yoon, Interdisciplinary Program in Biohealth-machinery Convergence Engineering, Physical Education, Kangwon National University, 1, Kangwondaehak-gil, Chuncheon-si, Gangwon-do, Republic of Korea; Tel: +82-33250-6787; Fax: +82-33-250-5680; E-mail address: tyoon@kangwon.ac.kr
이다[1]. 국내의 경우에도 19,530 건의 스포츠 활동 시 손상 사례를 분석한 결과, 슬관절 손상 중 가장 높은 발 생률(51\%)을 보이고 있다 [2]. 또한, ACL 부상은 수술 적 방법인 재건술을 받고도 성공적인 복귀를 위해서는 많은 돈과 장기간의 시간이 소요되는 심각한 부상이다 [3]. 따라서 ACL 부상 방지를 위한 방안은 반드시 마 련되어야 하며, 이를 위해서는 부상 기전에 대한 이해 
가 선행되어야 할 것이다[4]. 이에 무릎십자인대 부상 을 일으키기 쉬우며 스포츠 경기 상황에서 많이 발생하 는 방향전환, 점프 착지 등의 동작들을 대상으로 근신 경 생체역학의 다양한 방법을 이용하여 부상의 기전을 밝히는 연구들이 많이 이루어져왔다 [5,6].

스포츠 경기에서는 갑작스런 상황에 적응하거나 상 대 선수를 회피하기 위하여 방향전환 동작을 빈번하게 실시한다. 이때 발생하는 무를 부상은 운동기구나 다 른 선수와의 접촉으로 인한 부상보다는 비 접촉성 부상 (non-contact injury)이 더 많이 발생하는 것으로 보고 되고 있다[7]. 역학적인 관점에서 비 접촉성 부상으로 인한 무를 인대 파열은 무릎 인대에 가해진 부하가 인 대 강도를 초과할 때 발생하며, 인대의 강도는 호르몬 수치(hormone levels), 부하 이력(loading history), 이 전 부상 경험 등과 같은 많은 요인에 따라 달라진다[8]. 인대에 가해지는 부하는 무릎 관절에 외부 힘이 작용할 때 관절 표면의 운동학 및 기하학, 관절을 둘러싼 근육 의 활성화에 따라 달라진다. 따라서, 부상 위험을 줄이 는 한 가지 방법은 인대에 가해지는 하중에 영향을 미치 는 요인을 객관적으로 평가하는 것이다[8]. 이전의 연구 에서 스포츠 경기 동작 중에 무릎에 가해지는 외부 하중 을 특성화하기 위해 달리기, 사이드 스텝 및 교차 방향 전환 동작 시 관절에 가해지는 3 차원 모멘트가 측정되 었다. 그 결과, 무릎 관절의 굴곡, 외반 및 내부 회전의 결합된 모멘트는 전방 십자 인대에 가장 큰 부담을 주 는 것으로 알려져 있으며, 이는 방향전환 동작 중에 발 생한다고 보고 되었다[8].

무를을 둘러싼 근육은 관절에 가해지는 외부 하중이 나 충격으로부터 관절을 보호하고, 무릎이 움직일 때 개 개의 근육은 해부학적 모멘트 암을 변화시켜 인대에 가 해지는 부하를 적절히 감소시키는 역할을 한다[9]. 예 를 들어, 동적 착지 동작 중에 햄스트링 근육은 착지 전 에 미리 활성화되며 착지 직후 발생하는 대퇴골에 대한 경골의 전방 이동을 막아 $\mathrm{ACL}$ 을 보호하는 것으로 보고 되었다[10]. 하지만, 이러한 연구는 근전도 전극 부착 이 가능한 표면근육에 국한되며, 근육의 활성화를 측정 하여 간접적으로 근육의 힘을 추정할 수 밖에 없는 한 계가 있다. 즉, 관절을 지나는 모든 근육과 연결조직에 의한 결과적인 관절반력과 모멘트만을 계산할 수 있는 역동역학의 제한점을 부분적으로만 극복한 것으로, 많 은 분절(segments)과 근육들로 구성된 사람의 움직임
을 근육 단위별로 분석하는 데는 한계가 있다. 최근 컴 퓨팅 기술의 향상과 근골격모델링 프로그램의 등장으 로 신경근 골격계를 모델링하여 이전에는 풀리지 않았 던 많은 연구 질문을 탐구할 수 있게 되었다[11]. 이에 Maniar 등(2019)은[12] 근골격모델링 기법을 활용하 여 방향 전환 동작 시 하지 개별 근육의 힘을 분석하여 제시하였다. 하지만, 8명의 남성만을 대상으로 실시하 였기 때문에 결과를 일반화 시키기에 통계적 파워가 작 았으며, 무를 십자인대 부상 발생률이 여성이 4 9배 더 높게 나타나는 통계[13]를 고려했을 때 여성을 대상으 로 한 연구가 필요하다.

따라서, 본 연구의 목적은 여성을 대상으로 운동학 및 운동역학적 방법과 근골격계 모델링 기법을 활용하 여 러닝과 방향전환 동작 시 무를 주변의 하지 개별 근 육의 힘 발현 패턴을 비교하는 것이다. 본 연구의 결과 를 통해 향후 방향 전환 동작 시 하지 관절의 부상 방지 전략을 위한 훈련 프로그램의 기초자료를 제공할 수 있 을 것으로 기대한다.

\section{연구방법}

\section{1. 연구대상}

본 연구의 참여자로 주 2회 이상 정기적인 체육활 동에 참여하며 오른발을 우성발로 사용하고 있는 13 명의 여성을 모집하였다 $(24.2 \pm 3.5 \mathrm{yrs}, 162.8 \pm 6.0 \mathrm{~cm}$, $55.3 \pm 6.2 \mathrm{~kg}$ ). 또한, 본 연구의 참여자는 무릎관절을 포 함한 하지 근골격계의 부상 경력이 없으며, 평소 스포 츠 활동을 통하여 러닝을 비롯한 방향전환 동작의 숙련 자들이다. ACL 부상 확률이 남성보다 높다는 선행연구 에 따라 여성으로 선정하였으며[13], 통계적 파워와 선 행연구를 참고하여 연구대상자 수를 설정하였다[14]. 본 연구에 참여하는 모든 연구대상자의 권리와 안전을 보장하기 위하여 한국스포츠정책과학원 생명윤리위원 회의 연구승인을 받았으며 이를 준수하였다(IRB No. KISS-1810-044-01).

\section{2. 실험절차}

본 실험에 앞서 3 차원 동작분석이 수행될 공간의 3 차원 전역좌표계 설정을 위한 캘리브레이션을 실시하였 다. 이 과정에서 반사마커가 부착되어 있는 L자 프레임 으로 전역좌표계를 설정하였으며, T자 wand를 이용하 여 캡쳐 공간을 설정하였다. 모든 연구참여자에게는 설 
명서 및 동의서를 제공하며 연구의 목적, 실험과정, 개 인정보 보호 등과 관련된 전반적인 안내사항을 구두로 설명한 후 동의서에 자발적으로 서명할 수 있도록 안내 하였다. 모든 연구참여자는 실험 전 준비운동을 실시하 고, 실험 동작과 속도를 숙련된 조교의 시범과 함께 익 숙해질 때까지 충분한 연습을 실시하였다. 이후, 모션 캡처 시스템과 지면반력기의 신호를 확인하고 선행 논 문에 따라 총 51 개의 반사마커를 신체 관절과 분절 등 에 부착하였다[15].

러닝 동작과 방향전환 동작은 지면반력기를 기준으 로 $5 \mathrm{~m}$ 후방에서 출발하여 지면반력기 표면에 착지 순 간까지 $4.5 \pm 0.5 \mathrm{~m} / \mathrm{s}$ 의 속도가 되도록 통제하였다. 방 향전환은 우측 발이 정면을 향하도록 하여 지면반력기 에 착지한 후 진행방향의 $45^{\circ}$ 좌측으로 속도를 줄이지 않고 달려나가도록 요구하였다. 이때, 진행방향의 좌측 35 55범위로 수행한 것을 유효한 동작으로 채택하 였다[16]<Figure 1>. 각 조건의 동작은 무작위로 실시 하였으며, 실험 조건에 맞는 동작이 조건별 최소 3 회 이 루어졌다고 판단될 때까지 반복 측정하였다. 반복동작 으로 인한 피로 발생을 최소화하기 위해 각 5 회의 동작 후 또는 참여자의 요청으로 약 2 분간 자유로운 방법으 로 휴식을 취하게 하였다. 모든 동작은 모션 캡처 시스템 (Qualisys, Oqus 7+, Gothenburg, Sweden)과 지면반 력기(Kistler Type 9287BA, Winterthur, Switzerland) 를 이용하여 각각 $200 \mathrm{~Hz}$ 와 $1000 \mathrm{~Hz}$ 로 샘플링하였다.

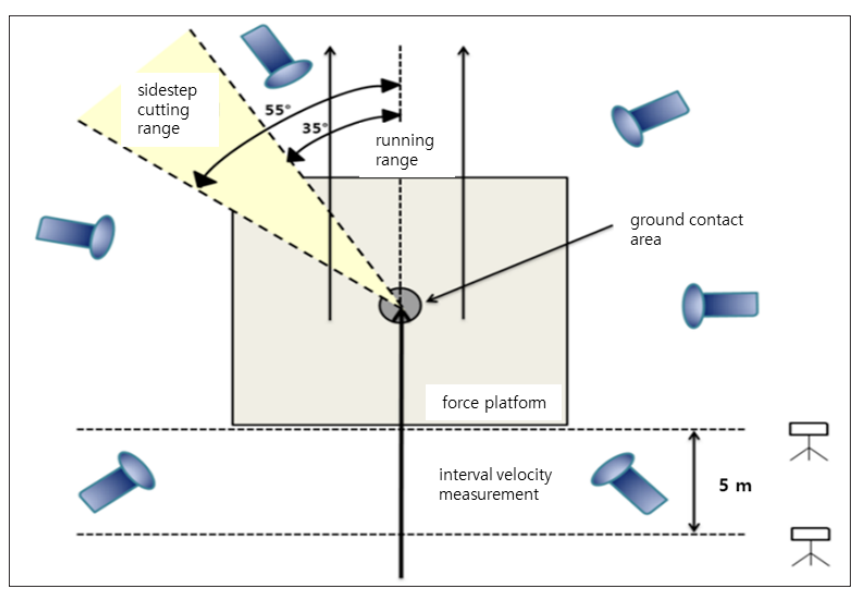

Figure 1. Structural diagram of cutting experiment $(26,34)$

\section{3. 자료처리 및 분석}

3 차원 모션캡쳐 시스템으로 획득한 원 자료 는 Qualysis Track Manager 프로그램(Qualysis,
Gothenburg, Sweden)을 사용하여 캡쳐과정에서 인식 되지 않았던 반사마커의 일부 누락된 정보를 수학적으 로 보정하는 작업을 수행하였다(17). 연구대상자의 동 작 수행 중 발생하는 모션 캡쳐 자료의 잡음(noise)을 제거하기 위하여 Butterworth 4th order 저역통과 필 터(lowpass filter, cut-off frequency at $15 \mathrm{~Hz}$ )를 적 용한 후 관절 중심점 산출을 위한 기초 정보로 이용하였 다[18]. 또한, 지면반력 신호에 포함된 잡음을 제거하 기 위하여 Butterworth 4th order 저역통과 필터(cutoff frequency at $15 \mathrm{~Hz}$ )를 적용하였다[18]. 신호처리 (signal process) 과정을 거쳐서 산출된 자료를 기반으 로 착지구간에서의 운동학적(신체 중심의 속도, 무릎관 절 각도) 및 운동역학적(지면반력, 무릎관절 모멘트) 데 이터를 산출하였다. 지면반력 데이터는 참여자의 체중 으로, 모멘트 데이터는 참여자의 체중과 신장으로 각각 표준화하였다[19]. 신호처리 과정과 운동학적 및 운동 역학적 결과 산출은 Visual3D(v6.01, C-Motion Inc. Rockville, USA) 프로그램을 활용하였다.

하지 개별 근육의 힘은 기존 골격계 모델(http://simtk. or/projects/opensim)에서 제공하는 러닝 모델(fullbody model Hamner2010)을 이용하여 산출하였다[20]. 이 모 델은 10 개의 분절, 23 자유도로 구성되어 있으며, 92 개 의 근육을 분석할 수 있다[21]. 하지 개별 근육의 힘을 산출하는 과정은 신체 스케일(body scaling), 역운동학 (inverse kinematics), 역동역학(inverse dynamics), 정적 최적화(static optimization), 잔차 제거(residual reduction algorithm: RRA) 로 구성된다[15]. 신체 스 케일로 본 연구에서 수정한 근골격계 모델에 각 연구대 상자의 키와 체중, 분절의 길이 및 무게 등의 신체 정 보를 대입하였으며, 역운동학으로 위치 좌표를 대입하 여 관절 각도를 산출 하였다. 이후, 역동역학 방법을 통 해 역운동학으로 산출된 관절 각도 기반의 관절력과 모 멘트를 산출하였다. 이후, 근육 힘은 근육-힘줄 단위 (musculotendinous units)의 생리적 힘-길이-속도 특 성을 고려하여 근육 활성화의 합을 제곱하여 최소화함 으로써 관절 모멘트를 개별 근육 힘으로 분해하는 정적 최적화 알고리즘을 통해 산출하였다. 이 근육 힘 추정 방 법은 계산이 효율적이며, 유사한 고충격 운동에서 근육 힘을 예측하는 연구에 사용되었다[21]. RRA는 측정에 포함된 오차를 최소화하는 잔차 제거 알고리즘으로 각 관절의 힘과 모멘트를 동적으로 최적화하였다[15]. 최 
종적으로 산출한 하지 개별 근육은 내측햄스트링(반건양 근(semitendinosus)과 반막양근(semimembranosus)의 합), 대퇴이두근의 장두(biceps femoris long head), 대 퇴이두근의 단두(biceps femoris short head), 대퇴직 근(rectus femoris), 내측광근(vastus medialis), 중간 광근(vastus intermedius), 외측광근(vastus lateralis), 내측비복근(gastrocnemius medialis), 외측비복근 (gastrocnemius lateralis)으로 구분하여 분석하였다 [22,23]. 모든 산출 변인은 3 회 실시한 값의 산술 평균 값을 구하여 최종 분석에 사용하였다.

모든 변인의 분석은 일반적인 러닝 주기의 분석 방법 을 기본으로 하였으나, 러닝과 방향전환의 비교를 용이 하게 하기 위해 방향전환을 연구한 선행논문 [8]을 일부 참고하였다. 예를 들어, 부하반응기(loading response) 는 체중수용기(weight acceptance), 선행논문의 pushoff는 중간지지기(midstance) 또는 지지국면의 중간으 로, 발꿈치떼기(heel off)와 발가락떼기(toe-off) 사이 는 이지기(foot-off 또는 final push-off)로 혼용하여 사용했다.

\section{4. 통계분석}

자료 처리를 통해 산출된 모든 변인에 대해 ShapiroWilk 검사를 실시하여 정규 분포 여부를 확인하였다. 산출된 변인의 러닝과 방향전환 동작 간의 차이를 검증 하기 위해 대응 표본 $\mathrm{T}$-검정을 실시하였다. 검정의 결 과 유의한 차이가 나타나는 개별 근육의 힘 변인에 대 해 방향전환 동작으로 인한 임상적인 영향을 평가하기 위해 Cohen's d 를 산출하였다. 효과크기는 $\mathrm{d} \geq 0.2$, 작 은 효과, $d \geq 0.5$, 보통 효과, $d \geq 0.8$, 큰 효과로 해석하였 다(24). 통계적 유의 수준은 $a=.05$ 로 설정하였으며, 모 든 통계 처리는 SPSS 24.0 통계프로그램(SPSS Inc., Chicago, IL, USA)을 사용하였다.

\section{결과}

\section{1. 운동학 및 운동역학적 분석}

모든 참여자의 지면반력기 착지구간까지의 접근 속 도는 본 연구에서 통제한 $4-5 \mathrm{~m} / \mathrm{s}$ 의 범위에 들어왔다. 러닝과 방향전환 동작 시 착지구간에서의 신체중심의 평 균 이동속도는 각각 $4.75 \pm 0.27 \mathrm{~m} / \mathrm{s}$ 과 $4.47 \pm 0.37 \mathrm{~m} / \mathrm{s}$ 로 차이가 없었다( $\mathrm{p}>.05)$. 또한, 모든 피험자가 $35^{\circ} \sim 45^{\circ}$ 의 범위로 방향전환을 하였다.
방향전환과 러닝 시 지지구간에서의 무릎의 각도, 지 면반력, 모멘트 변화 양상은 그림 $2,3,4$ 에 나타나있다. 무릎관절 굽힘 범위는 방향전환 동작 시 $30.17 \pm 9.8^{\circ}(-$ $\left.47.8^{\circ} \sim-17.6^{\circ}\right)$, 러닝 동작 시 $22.83 \pm 7.58^{\circ}\left(-45.9^{\circ} \sim\right.$ $\left.-23.1^{\circ}\right)$ 로 방향전환 동작 시 더 큰 범위의 굽힘 동작을 한 것으로 나타났다 $(\mathrm{t}=3.344, \mathrm{p}<.01)$. 무릎관절의 평균 외반(valgus) 각도는 방향전환 동작이 러닝에 비해 지지 구간에서 전반적으로 작았다 $(\mathrm{t}=-28.12, \mathrm{p}<.001)$. 무릎 관절의 평균 외회전 각도는 방향전환 동작이 러닝에 비 해 더 컸다 $(\mathrm{t}=-8.967 \mathrm{p}<.001)$. 무릎관절 외회전 각도 범 위는 방향전환 동작 시 $12.30 \pm 3.80^{\circ}\left(-3.6^{\circ} \sim-15.9^{\circ}\right)$, 러닝이 $9.31 \pm 2.70^{\circ}\left(-3.5^{\circ} \sim-12.9^{\circ}\right)$ 로 방향전환 동작이 더 큰 범위로 내회전 하였다 $(\mathrm{t}=2.649, \mathrm{p}<.05)$.

\section{.}
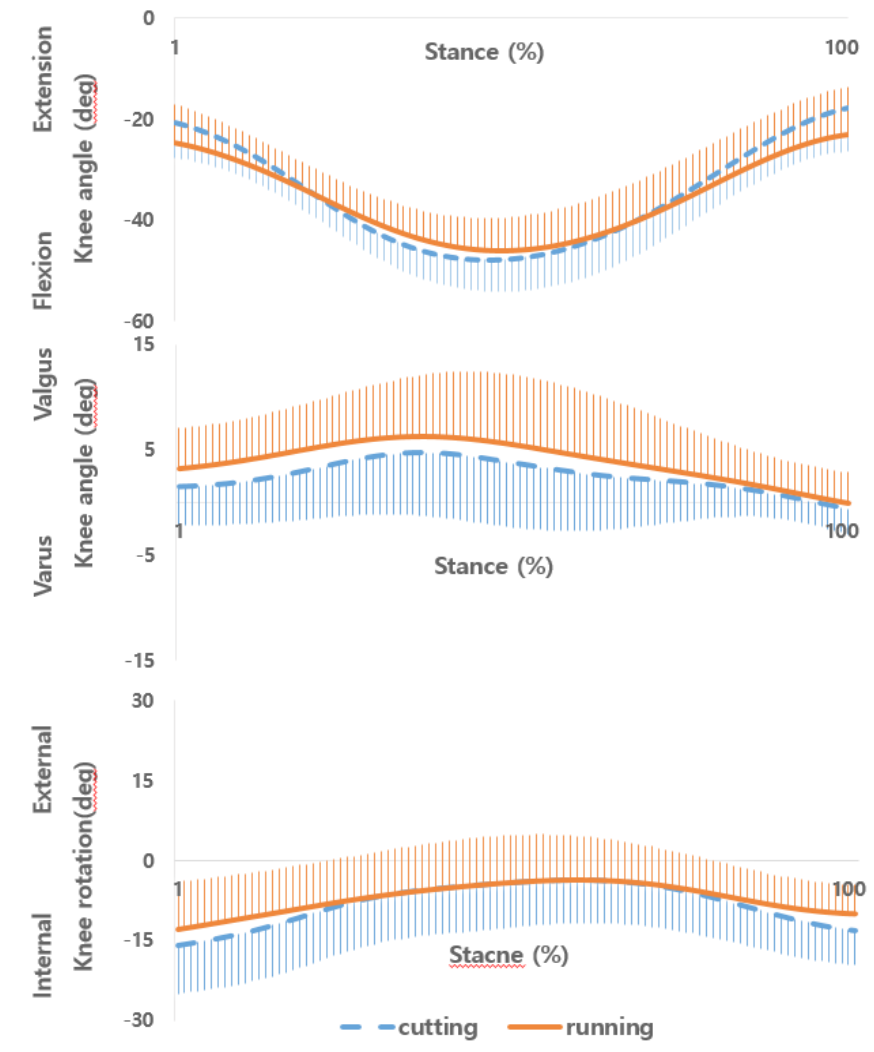

Figure 2. Knee joint angles during running and cutting

내외측(medial/lateral) 지면반력의 경우 러닝에 비 해 방향전환 동작이 외측방향으로 더 큰 변화를 나타 냈다 $(\mathrm{t}=-19.23, \mathrm{p}<.001)$. 전후 방향의 지면반력의 경 우 착지 초기에는 방향전환 동작이 러닝에 비해 제동 방향의 지면반력이 더 컸지만 이후 추진방향의 지면반 력은 러닝이 더 컸다. 결과적으로 지지구간의 전체적인 평균은 통계적으로도 유의한 차이를 보였다 $(\mathrm{t}=-18.22$, 


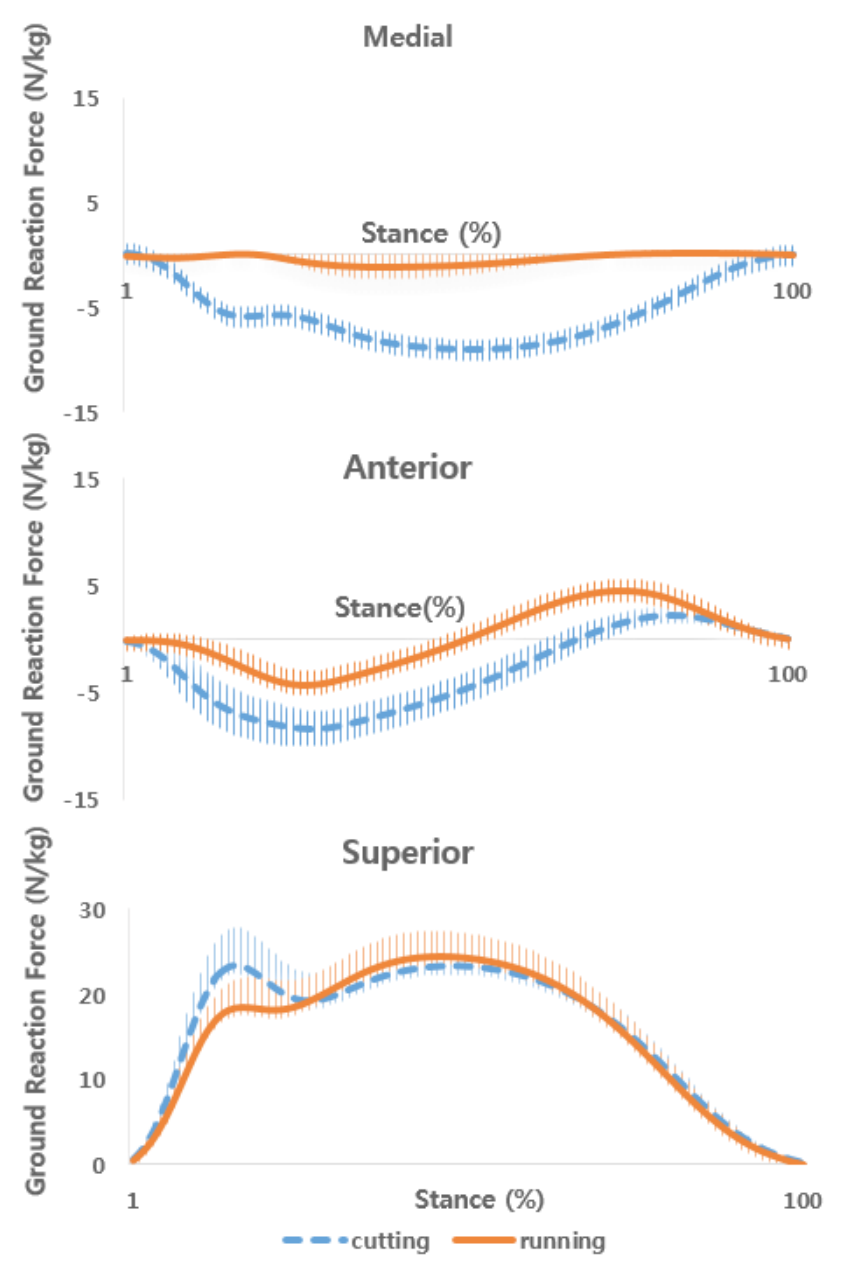

Figure 3. Ground reaction force during running and cutting

$\mathrm{p}<.001)$. 상하 방향의 지면반력의 경우 러닝과 방향전환 동작 시 유의한 차이가 나타났으며 $(\mathrm{t}=-17.00, \mathrm{p}<.01)$, 초기 착지에서 방향전환 동작이 러닝에 비해 더 큰 수

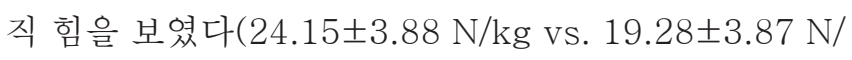
$\mathrm{kg}, \mathrm{t}=2.973 \mathrm{p}<.01)$.

무릎관절의 평균 신전 모멘트는 방향전환 동작이 러 닝에 비해 더 컸으며 $(\mathrm{t}=10.53, \mathrm{p}<.001)$, 무릎관절의 평 균 내반(varus) 모멘트는 러닝이 방향전환 동작에 비해 더 컸다 $(\mathrm{t}=21.55, \mathrm{p}<.001)$. 특히, 방향전환 동작 시 착 지 초기에 외반 모멘트가 더 컸으며 내반 모멘트로 변 환되고 이후 이지 시까지 다시 외반 모멘트로 변화하는 양상을 보였다. 무릎관절의 평균 내회전 모멘트는 방향 전환 동작이 러닝에 비해 더 컸다 $(\mathrm{t}=6.504, \mathrm{p}<.001)$.

\section{2. 개별 근육의 힘 분석}

지지구간에서 햄스트링 근육을 제외한 모든 근육의
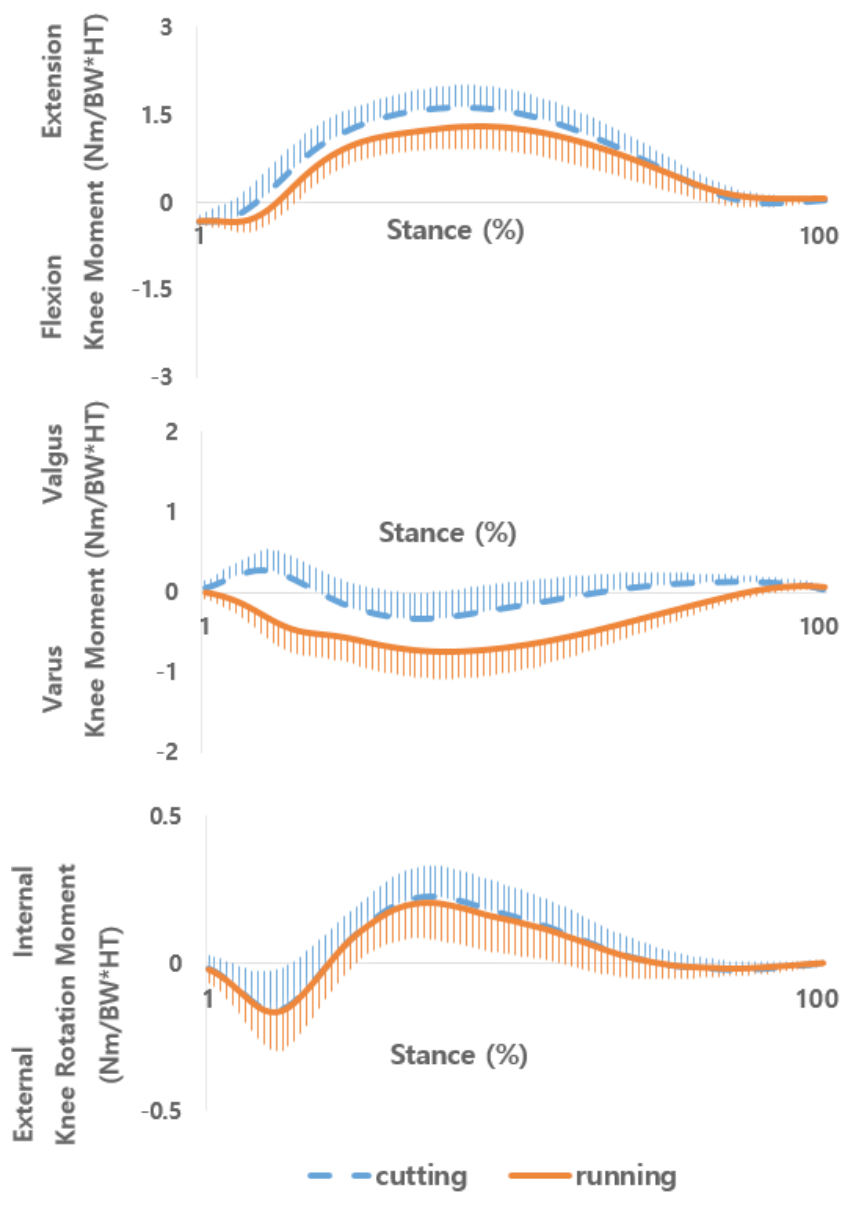

Figure 4. Knee joint moments during running and cutting

평균힘은 러닝보다방향 전환 동작 시에 더 크게 나타났 다<Table 1>. 햄스트링 내측근육(반건양근과 반막양근 의 합)의 힘은 체중수용기에 최대값을 보인 후 지지구 간의 중간에서 감소하여 지지구간 후반에서 발의 이지 시까지 다시 증가하는 패턴을 나타냈다. 대퇴이두근의 장두(BFLH)도 햄스트링 내측근육과 유사한 패턴을 보 였으나 체중수용기의 최대값은 러닝 시보다 약 2 배 크

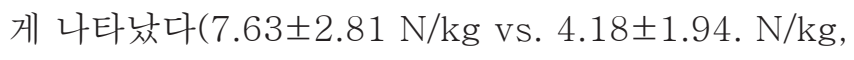
$\mathrm{t}=3.256, \mathrm{p}<0.01, \mathrm{~d}=1.43)$. 대퇴이두근의 단두(BFSH) 는 접지 이전부터 높은 값을 보였으며 다른 햄스트링 근 육과는 달리 체중수용기에 피크 형태가 나타나지 않았 다. 대퇴직근의 경우 체중수용기가 끝나는 시점에서 증 가되는 양상을 보였으며 지지구간 중반부터 증가하여 최대값이 러닝의 2 배에 이른 후 이지 시까지 다시 감 소했다. 내측광근, 중간광근, 외측광근은 접지 후 증가 하고 체중수용기 이후에도 재차 증가하여 최고점에 이 

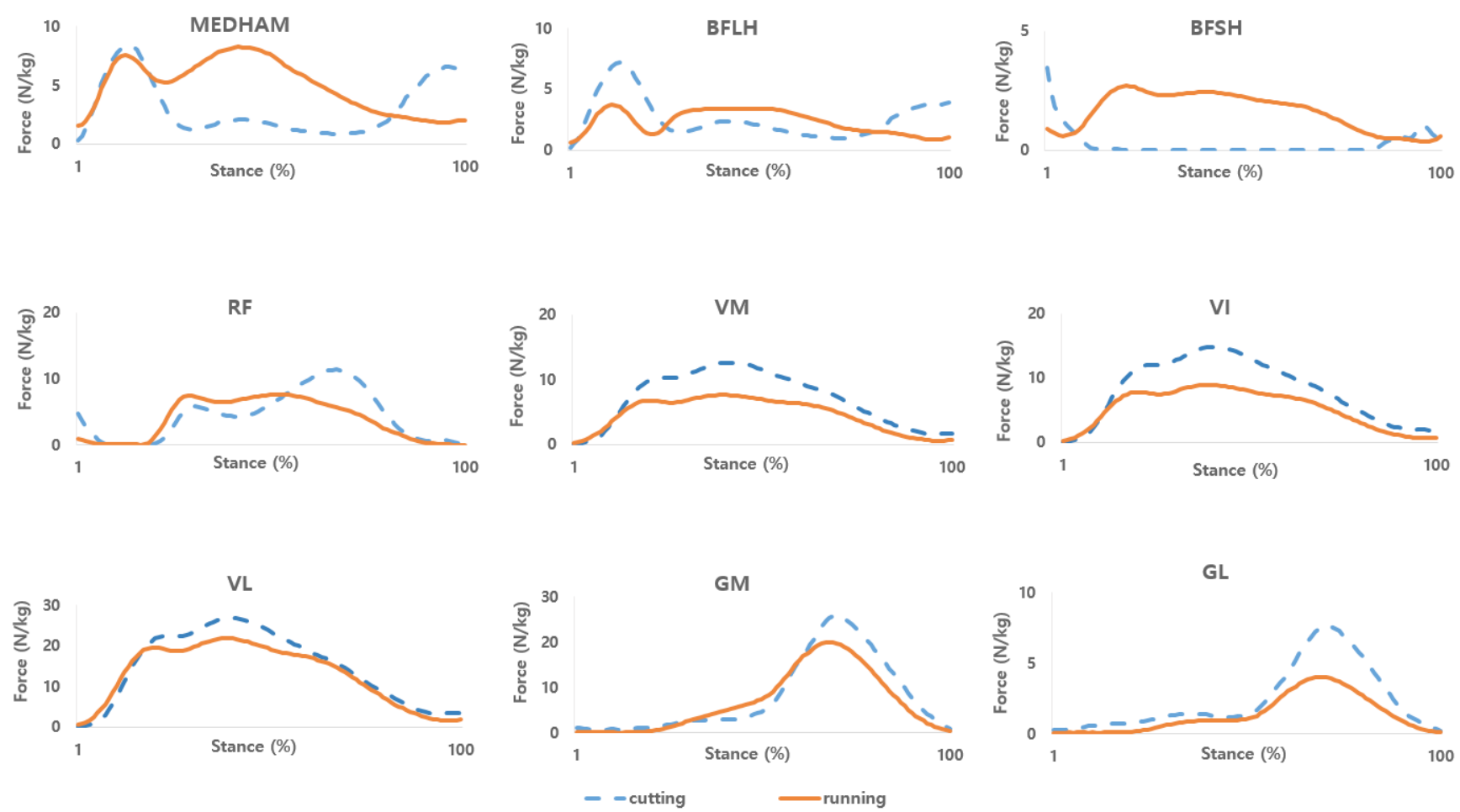

Figure 5. The individual muscle forces of the knee joint during running and cutting MedHam, Medial Hamstring (sum of semitendinosus, semimembranosus); BFLH, biceps femoris long head; $B F S H$, biceps femoris short head; $R F$, rectus femoris; $V M$, vastus medialis; VI, vastus intermedius; VL, vastus lateralis; $G M$, gastrocnemius medialis; $G L$, gastrocnemius lateralis..

Table 1. Comparison of the mean force of individual muscles of the lower-limb in the stance during running and cutting

\begin{tabular}{|c|c|c|c|c|c|}
\hline \multirow{2}{*}{ Variable } & \multicolumn{2}{|c|}{ Task } & \multirow{2}{*}{$t$} & \multirow{2}{*}{$p$-value } & \multirow{2}{*}{$\begin{array}{l}\text { Cohen's } \\
\text { d }\end{array}$} \\
\hline & Cutting & Running & & & \\
\hline MedHam & $3.08 \pm 2.37^{* * *}$ & $4.97 \pm 2.24$ & -5.522 & .000 & 0.82 \\
\hline BFLH & $2.60 \pm 1.68$ & $2.31 \pm 0.95$ & 1.598 & .113 & 0.21 \\
\hline BFSH & $0.24 \pm 0.54^{* * *}$ & $1.60 \pm 0.80$ & -11.65 & .000 & 2.00 \\
\hline$R F$ & $4.37 \pm 3.68^{*}$ & $3.77 \pm 3.04$ & 2.434 & .017 & 0.18 \\
\hline$V M$ & $7.10 \pm 4.08^{* * *}$ & $4.63 \pm 2.52$ & 14.57 & .000 & 0.73 \\
\hline VI & $8.17 \pm 4.79^{* * *}$ & $5.32 \pm 2.96$ & 14.44 & .000 & 0.72 \\
\hline$V L$ & $14.83 \pm 8.74^{* * * *}$ & $13.03 \pm 7.27$ & 8.466 & .000 & 0.22 \\
\hline GM & $8.05 \pm 8.31^{* * *}$ & $6.85 \pm 6.69$ & 4.487 & .000 & 0.16 \\
\hline GL & $2.44 \pm 2.31^{* * * *}$ & $1.34 \pm 1.30$ & 10.25 & .000 & 0.60 \\
\hline
\end{tabular}

Note: Unit: $N / \mathrm{kg}^{*}{ }^{*} p<.05,{ }^{* * *} p<.001$, MedHam, Medial Hamstring (sum o semitendinosus, semimembranosus); $B F L H$, biceps femoris long head; $B F S H$, biceps femoris short head; $R F$, rectus femoris; $V M$, vastus medialis $V I$, vastus intermedius; $V L$, vastus lateralis; $G M$, gastrocnemius medialis; $G L$, gastrocnemius lateralis.

른 후 이지 시까지 다시 감소하는 양상을 보였다. 내측 광근, 중간광근, 외측광근은 지지구간에서 방향전환 동 작 시 평균값이 러닝 시보다 더 컸다 $(\mathrm{t}=14.57, \mathrm{p}<.001$; $\mathrm{t}=14.44, \mathrm{p}<.001 ; \mathrm{t}=8.466, \mathrm{p}<.001)$. 내측비복근과 외 측비복근은 지지구간의 중반 이후 증가하여 약 $70 \%$ 시 점에서 피크값을 보인 후 이지 시까지 다시 감소하는 양 상을 보였다. 두 조건 모두 비슷한 양상을 보였지만, 방 향전환 동작 시 최대값이 러닝 조건과 비교해 내측비복

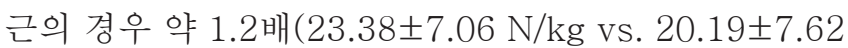
$\mathrm{N} / \mathrm{kg}, \mathrm{t}=2.863, \mathrm{p}<0.05, \mathrm{~d}=1.12)$, 외측비복근의 경우 약 2 배(8.23 $\pm 3.89 \mathrm{~N} / \mathrm{kg}$ vs. $4.10 \pm 1.58 \mathrm{~N} / \mathrm{kg}, \mathrm{t}=3.429$, $\mathrm{p}<0.01, \mathrm{~d}=1.39)$ 크게 나타났다.

\section{논의}

본 연구는 여성을 대상으로 근골격계 모델링 기법을 활용하여 러닝과 방향전환 동작 시 하지 개별 근육의 힘 발현 패턴을 비교하였다. 연구를 통해 운동학, 운동역학, 개별 근육 힘의 패턴에서 차이가 나타났으며 자세한 논 의는 아래와 같다.

본 연구에서 무릎의 굴곡 각도는 러닝과 비교하여 방 향전환 동작 시 무릎을 덜 굴곡한 상태에서 착지하고 더 많이 굴곡한 후 다시 신전하는 양상을 보였다. 이는 직 
선으로 가는 러닝과 달리 방향전환 각도가 커질수록 무 릎의 굽힘의 정도가 커진다는 선행연구와 유사한 결과 로 보인다[3]. 무를 굽힘과 연관된 부하(load)는 무를 인대 손상의 잠재적인 위험을 가지고 있다고 보고되었 으나[25], 시상면에서의 관절반력이 $\mathrm{ACL}$ 의 파열과 관 련이 적다는 선행연구의 결과를 고려할 때 무릎 굴곡/신 전의 부상에 대한 연관성은 크지 않은 것으로 사료된다 [26]. 무릎관절의 외반 각도는 방향전환 동작이 러닝보 다 더 작게 나타났는데, 이는 착지 시 작은 외반각을 형 성하여 상해를 방지하기 위한 전략이라 판단된다 (19). 무릎관절의 외측 회전 각도의 경우 여성 선수들의 $\mathrm{ACL}$ 부상 예측의 중요한 인자로 보고 되었는데[27], 본 연 구의 경우 러닝보다 방향전환 동작의 착지와 이지 단계 에서 더 큰 값이 나타났으며, 특히 원심성 수축이 발생 하는 착지 후 체중수용기가 부상의 위험과 관련이 높을 것으로 판단된다.

러닝과 방향전환 동작에서 지면반력 변인은 체중지 지구간동안 발생한 지면반력을 설명하는 중요한 요인이 며 [28], 본 연구의 내외측의 지면반력은 러닝과 비교해 방향전환 동작에서 외측으로 큰 변화가 나타났다. 전후 방향의 지면반력의 경우, 착지 구간의 속도 감소와 추진 력을 알 수 있는 힘으로 착지 초기에는 방향전환 동작이 러닝보다 더 컸지만 추진력은 러닝이 더 컸다. 이는 방 향전환 동작은 러닝과 달리 방향전환을 위한 제동력이 작용하였고, 러닝은 추진력이 진행방향으로 발생하였는 데 방향전환 동작은 방향을 전환함으로써 추진력이 손 실된 결과로 보인다[29]. 지면반력의 수직 힘은 초기 착 지 구간에 방향전환 동작이 러닝보다 더 컸는데, 이러한 이유 역시 앞에서 언급한 바와 같이 방향전환 동작 특 성상 제동력이 러닝보다 큰 이유 때문인 것으로 판단된 다. 방향전환 동작 시 지면반력에 나타난 이러한 변화 는 방향전환 동작을 원활하게 수행함으로써 나타난 것 이나 부상과 관련하여 관련성을 규명하는 연구 또한 필 요할 것으로 사료된다.

사이드 스텝핑 및 크로스오버 커팅과 같은 동작은 무 릎의 굴곡/신전, 내반/외반, 내/외회전 모멘트의 다양한 조합을 포함하므로 직선 주행에 비해 연조직과 지지구 조에 다른 부하를 가할 것으로 예상되었다[30]. 러닝과 방향전환 동작 시 무릎에 가해지는 외부 부하에 대한 연 구에서 이를 입증하였는데 러닝과 비교해서 사이드 스 테핑과 크로스오버 커팅 동작은 더 큰 내/외반 모멘트
와 내/외회전 모멘트를 증가시켜 인대에 가해지는 부하 를 높인다고 보고하였다[30]. 무릎에 가해지는 큰 굴곡 부하에 대응하기 위해 관절을 둘러싼 근육은 무릎이 거 의 완전히 신전될 때 경골에 순 전방 힘을 초래할 수 있 는 신전 모멘트를 적용해야 하는데 본 연구에서 무릎관 절의 신전 모멘트는 방향전환 동작이 러닝에 비해 더 컸 다. 이는 본 연구의 무릎관절의 굴곡 각도 결과의 논의 에서와 마찬가지로 무릎 굴곡/신전의 부상에 대한 연관 성은 아주 크지 않은 것으로 사료된다[26]. 무릎관절의 외반 움직임을 상쇄하기위해 발생되어야 하는 내반 모 멘트는 무릎관절의 ACL 상해 위험성을 알 수 있는 지 표로 본 연구에서 러닝이 방향전환 동작에 비해 더 큰 것으로 나타나 상대적으로 외반 모멘트가 큰 방향전환 동작이 부상의 위험에 더 크게 노출 되어 있는 것으로 보인다. 특히, 착지 순간부터 체중 지지기 동안 방향전 환 동작에서 크게 나타나는 것은 비접촉 ACL부상과 관 련하여 주목할 만한 점이다. 체중과 신장으로 표준화한 외반 모멘트의 경우 여성이 남성보다 크게 나타나 여성 이 ACL부상에 취약한 주요 원인이 되기 때문이다[19].

방향전환 동작 시 무릎의 동적 안정성을 확보를 위 해 무릎을 둘러싼 내/외측, 내/외회전 근육의 선택적인 활성과 함께 굴곡/신전근의 동시수축(co-contraction) 이 증가한다[8]. 예를 들어, 방향전환으로 인한 대퇴경 골관절(tibiofemoral joint)의 내/외측에 작용하는 내/외 반 모멘트를 상쇄하여 관상면에서의 움직임을 안정화시 키기 위해, 지지구간의 체중수용기에서 내측광근과 외 측광근의 선택적인 활성이 나타난다. 본 연구의 경우도 내외측 광근의 힘은 착지 직후 일차적인 증가를 하였으 며, 이러한 선택적인 근부하의 증가는 대퇴이두근의 장 두와 단두에서도 두드러지게 나타났다. 광근은 기본적 으로 무를의 신전을 담당하지만 각각의 해부학적인 위 치에 따라 무릎관절이 20 50\% 사이에서 내측광근은 내 반과 내회전근, 외측광근은 외반과 외회전근으로도 각 각 작용을 한다. 이는 각각 내반과 내회전, 외반과 외회 전에 기여하는 내측햄스트링과 외측햄스트링의 경우도 마찬가지이다[8]. 따라서, 체중수용기에 나타난 내외측 근육들의 힘증가는 방향전환 동작으로 인해 증가된 외 부부하로부터 무릎관절을 보호하기 위한 것으로 사료된 다. 특히, 방향전환 시 상대적으로 큰 햄스트링의 외측 근육의 힘은 선행논문에서와 같이 무를 부상의 주요 원 인으로 보고된 내회전을 상쇄하기 위한 외회전에 유의 
미한 기여를 하는 것으로 판단된다[31].

체중수용기 이후 대퇴사두근의 힘은 계속 증가하여 지지국면의 중간에 이르러 대퇴직근을 제외한 세 개의 광근의 힘이 최고점에 이르렀다. 특히, 러닝과 비교하여 방향전환 시 내측광근의 증가가 두드러지며, 이러한 경 향은 중간광근에서도 나타났다. 이는 여자의 경우 외측 광근의 활성이 내측광근보다 더 크고 남자의 경우는 반 대로 나타났다고 보고한 선행논문의 결과와는 다소 다 르게 나타났다(31). 이렇게 상이한 결과는 두 연구 간의 과제(진행할 방향을 사전에 알고 있는지 여부)의 차이 에 따른 것으로 사료되며 정확한 인과관계는 후속연구 를 통해 밝혀져야 할 것이다. 대퇴사두근의 선택적 증 가와는 반대로 방향전환 시 내측햄스트링 근육과 외측 햄스트링 근육(특히, 대퇴이두근의 단두)의 힘은 현저히 감소하여 지지기 후반에 다시 증가하게 된다. 햄스트링 근육과 비교하여 대퇴사두근의 상대적으로 더 큰 증가 는 남자보다는 여자축구 선수들에게서 더 크게 나타나 여성의 높은 ACL부상률과의 가능성을 제시한 선행연 구의 결과와 유사하다[32]. 하지만, ACL 부상 발생 시 기가 착지 직전과 체중수용기로 보고하였으며, 이는 본 연구와 달라 성별에 따른 부상 위험 인자로 볼 수 있는 지는 후속 연구가 필요한 것으로 사료된다.

본 연구에서 지지구간의 중반 이후 근육 힘 발현의 두 드러진 특징은 내측비복근과 외측비복근의 힘 증가이다. 특히, 외측비복근의 힘 증가는 러닝과 비교하여 방향전 환 동작 시 최고 값이 두 배에 이를 정도로 그 변화가 크 게 나타났다. 이러한 패턴은 선행연구의 결과와 일치하 며 [31], 지지구간의 중반이후에는 원위쪽 근육의 역할 이 커진 것이라 할 수 있다. 지지구간의 중후반부의 외측 비복근의 활성 증가가 직접적으로 $\mathrm{ACL}$ 부상과 관련이 있는지는 본 연구의 결과로 확인할 수는 없다. 하지만, 사전에 진행 방향을 알지 못하는 방향전환 과제에서 여 성이 남성보다 외측비복근의 활성도가 높았다는 선행연 구를 고려할 때[31], 단순한 성별의 차이인지 아니면 부 상과 관련이 있는지를 규명하는 후속 연구가 필요하다.

본 연구는 다음과 같은 연구제한점이 있다. 첫째, 러 닝과 방향전환 동작과 같은 동적 움직임은 상체의 움직 임과 엉덩관절, 무릎관절, 발목 관절의 유기적인 움직 임으로 이루어 지는데, 본 연구는 무릎관절과 주변 근 육으로 제한하여 관련 변인을 조사하였다. 이는 선행연 구와 마찬가지로 $\mathrm{ACL}$ 부상 관련이 깊은 무릎관절의 근
육에 중점을 두기 위한 것이나[22], 향후 방향전환 동 작에 영향을 미치는 모든 신체의 영향을 고려한 추가적 연구가 진행되어야 할 것이다. 둘째, 본 연구에서 사용 한 근골격계 모델링 기법은 각 연구참여자의 신체 정보 를 기반으로 한 운동역학적 파라미터를 입력하고, 근육 힘 추정 방법을 사용하여 최종 변인을 산출하였다. 따 라서, 적용한 개별적 모델의 오차가 있을 수 있어서 표 면 근전도 자료를 동시에 샘플링하고 분석하여 타당성 을 검증을 하는 것이 이상적이다. 하지만 기술적인 문제 로 표면 근전도 자료를 분석하지 못하였으며 연구 결과 의 해석에 주의를 요한다. 다만, 본 연구에서 사용한 방 법은 모델의 유효성이 검증된 선행연구들을 참조하였으 며 [33,34], 전체적인 결과가 근전도를 사용한 연구결과 들과 비슷한 패턴을 보였다는 점을 밝힌다. 셋째, 본 연 구의 연구 대상자가 여성에 국한하였다. ACL부상에 취 약한 여성을 대상으로 하였으나, 비교할 남성 또는 부상 경력이 있는 여성 등의 대상이 없어 직접적으로 방향전 환으로 인한 위험 인자를 규명할 수는 없었다.

\section{결론}

본 연구는 여성을 대상으로 근골격계 모델링 기법을 사용하여 러닝과 방향전환 동작 시 하지 개별 근육의 힘 발현 패턴을 비교하고자 하였다. 본 연구결과 방향전환 으로 발생한 외부 부하를 상쇄하기 위해 무릎을 둘러싼 모든 근육이 선택적인 힘 발현 패턴을 보였다. 요약하 자면, 러닝과 비교하여 방향전환 동작 시 1) 착지 초기 의 외측 햄스트링 근육의 힘 증가, 2) 체중수용기 이후 햄스트링 근육의 힘 감소와 내측 광근의 힘 증가, 3) 지 지국면 중반 이후의 외측비복근의 힘이 증가하는 패턴 이 나타났다. 본 연구의 결과가 향후 방향전환 동작 시 하지 관절의 부상 방지 전략을 위한 훈련 프로그램의 기 초자료로 제공되기를 기대한다.

\section{Acknowledgments}

이 논문은 2021년 춘천교육대학교 국립대학 육성지 원사업의 지원을 받아 수행되었음

\section{References}

1. Musahl V, Karlsson J. Anterior Cruciate Ligament Tear. N 
Engl J Med. 2019;380(24):2341-8.

2. Park YR, Son YH, Yang SJ, Seo YH. The Effects of Props Rehabilitation Exercise Program on the Stability, Femoral Circumference, and Knee Muscle Development of Athletes who Underwent Anterior Cruciate Ligament Reconstruction. Korean Society Of Growth And Development. 2017;25(2):265-9.

3. Kim KH, Cho JH. The Influence of Cutting Direction on Risk Factors of Anterior Cruciate Ligament Injury. Journal of Sport and Leisure Studies. 2012;48(2):795802.

4. Dai B, Mao D, Garrett WE, Yu B. Anterior cruciate ligament injuries in soccer: Loading mechanisms, risk factors, and prevention programs. J Sport Health Sci. 2014;3(4):299-306.

5. Dai B, Herman D, Liu H, Garrett WE, Yu B. Prevention of ACL injury, part I: injury characteristics, risk factors, and loading mechanism. Res Sports Med. 2012;20(34):180-97.

6. Waldén M, Krosshaug T, Bjørneboe J, Andersen TE, Faul O, Hägglund M. Three distinct mechanisms predominate in non-contact anterior cruciate ligament injuries in male professional football players: a systematic video analysis of 39 cases. Br J Sports Med. 2015;49(22):145260.

7. Agel J, Palmieri-Smith RM, Dick R, Wojtys EM, Marshall SW. Descriptive epidemiology of collegiate women's volleyball injuries: National Collegiate Athletic Association Injury Surveillance System, 1988-1989 through 2003-2004. J Athl Train. 2007;42(2):295.

8. Besier TF, Lloyd DG, Ackland TR. Muscle activation strategies at the knee during running and cutting maneuvers. Med Sci Sports Exerc. 2003;35(1):119-27.

9. Andriacchi T, Andersson G, Örtengren R, Mikosz R. A study of factors influencing muscle activity about the knee joint. J Orthop Res. 1983;1(3):266-75.

10. Cowling EJ, Steele JR. Is lower limb muscle synchrony during landing affected by gender? Implications for variations in ACL injury rates. J Electromyogr Kinesiol. 2001;11(4):263-8.

11. Smale KB, Conconi M, Sancisi N, Alkjaer T, Krogsgaard
MR, Castelli VP, et al. Relationship of Knee Forces to Subjective Function Pre and Post ACL Reconstruction. Med Sci Sports Exerc. 2019.

12. Maniar N, Schache AG, Cole MH, Opar DA. Lower-limb muscle function during sidestep cutting. J Biomech. 2019;82:186-92.

13. Donnelly CJ, Chinnasee C, Weir G, Sasimontonkul S, Alderson J. Joint dynamics of rear- and fore-foot unplanned sidestepping. J Sci Med Sport. 2017;20(1):327.

14. Cortes N, Morrison S, Van Lunen BL, Onate JA. Landing technique affects knee loading and position during athletic tasks. J Sci Med Sport. 2012;15(2):175-81.

15. Delp SL, Anderson FC, Arnold AS, Loan P, Habib A, John CT, et al. OpenSim: open-source software to create and analyze dynamic simulations of movement. IEEE Trans Biomed Eng. 2007;54(11):1940-50.

16. Weinhandl JT, Earl-Boehm JE, Ebersole KT, Huddleston WE, Armstrong BSR, O’Connor KM. Anticipatory effects on anterior cruciate ligament loading during sidestep cutting. Clin Biomech 2013;28(6):655-63.

17. Rahimi A, Arab AM, Nourbakhsh MR, Hosseini SM, Forghany S. Lower limb kinematics in individuals with chronic low back pain during walking. J Electromyogr Kinesiol. 2020;51:102404.

18. Donnelly CJ, Lloyd DG, Elliott BC, Reinbolt JA. Optimizing whole-body kinematics to minimize valgus knee loading during sidestepping: implications for ACL injury risk. J Biomech. 2012;45(8):1491-7.

19. McLean SG, Huang X, Van Den Bogert AJ. Association between lower extremity posture at contact and peak knee valgus moment during sidestepping: implications for ACL injury. Clin Biomech. 2005;20(8):863-70.

20. Hamner SR, Seth A, Delp SL. Muscle contributions to propulsion and support during running. J Biomech. 2010;43(14):2709-16.

21. Dorn TW, Lin YC, Pandy MG. Estimates of muscle function in human gait depend on how foot-ground contact is modelled. Comput Methods Biomech Biomed Engin. 2012;15(6):657-68.

22. Killen B, Saxby D, Fortin K, Gardiner B, Wrigley T, Bryant 
A, et al. Individual muscle contributions to tibiofemoral compressive articular loading during walking, running and sidestepping. J Biomech. 2018;80:23-31.

23. Maniar N, Schache AG, Sritharan P, Opar DA. Non-kneespanning muscles contribute to tibiofemoral shear as well as valgus and rotational joint reaction moments during unanticipated sidestep cutting. Sci. 2018;8(1):110.

24. Cohen J. Statistical power analysis for the behavior science: Lawrance Eribaum association. Cambridge: Academic Press Books-Elsevier; 1988.

25. Shin SH, Park HC. Dynamics of Angular Running Turns in Foot Effectiveness. Korean J Sports Biomech. 2009;19(4):663-9.

26. McLean SG, Huang X, Su A, Van Den Bogert AJ. Sagittal plane biomechanics cannot injure the ACL during sidestep cutting. Clin Biomech. 2004;19(8):828-38. Epub 2004/09/03.

27. Hewett TE, Myer GD, Ford KR, Heidt Jr RS, Colosimo AJ, McLean SG, et al. Biomechanical measures of neuromuscular control and valgus loading of the knee predict anterior cruciate ligament injury risk in female athletes: a prospective study. Am J Sports Med. 2005;33(4):492-501.

28. Sigward SM, Cesar GM, Havens KL. Predictors of frontal plane knee moments during side-step cutting to 45 and 110 men and women: Implications for ACL injury. CJSM: Official Journal of the Canadian Academy of Sport Medicine. 2015;25(6):529.

29. Nachbauer W, Nigg BM. Effects of arch height of the foot on ground reaction forces in running. Med Sci Sports Exerc. 1992;24(11):1264-9.

30. Besier TF, Lloyd DG, Cochrane JL, Ackland TR. External loading of the knee joint during running and cutting maneuvers. Med Sci Sports Exerc. 2001;33(7):1168-75.

31. Beaulieu ML, Lamontagne M, Xu L. Lower limb muscle activity and kinematics of an unanticipated cutting manoeuvre: a gender comparison. Knee Surg Sports Traumatol Arthrosc. 2009;17(8):968-76.

32. Hanson AM, Padua DA, Troy Blackburn J, Prentice WE, Hirth CJ. Muscle activation during side-step cutting maneuvers in male and female soccer athletes. J Athl Train. 2008;43(2):133-43.

33. Hicks JL, Uchida TK, Seth A, Rajagopal A, Delp SL. Is my model good enough? Best practices for verification and validation of musculoskeletal models and simulations of movement. J Biomech Eng. 2015;137(2).

34. Lee J, Pathak P, Panday SB, Moon J. Effect of Foot-Planting Strategy on Anterior Cruciate Ligament Loading in Women During a Direction Diversion Maneuver: A Musculoskeletal Modeling Approach. Orthopaedic J Sport Med. 2020;8(11):2325967120963180. 